\title{
Median-to-Ulnar Nerve Communication in Carpal Tunnel Syndrome: An Electrophysiological Study
}

\author{
Vincenzo Di Stefano ${ }^{1, *(\mathbb{D})}$, Andrea Gagliardo ${ }^{1}$, Filomena Barbone ${ }^{2}$, Michela Vitale ${ }^{2}$, Laura Ferri ${ }^{2}{ }^{\mathbb{D}}$, \\ Antonino Lupica ${ }^{1}{ }^{\mathbb{D}}$, Salvatore Iacono ${ }^{1} \mathbb{D}$, Antonio Di Muzio ${ }^{3}$ and Filippo Brighina ${ }^{1}$ \\ 1 Department of Biomedicine, Neuroscience and Advanced Diagnostic (BIND), University of Palermo, \\ 90127 Palermo, Italy; andrigl@gmail.com (A.G.); antlupica@gmail.com (A.L.); Salvo.iak@gmail.com (S.I.); \\ filippobrighina@gmail.com (F.B.) \\ 2 Department of Neuroscience, Imaging and Clinical Sciences, "G. d'Annunzio" University, 66013 Chieti, Italy; \\ agapefilo@gmail.com (F.B.); michela.vitale1@yahoo.it (M.V.); ferrilaura@outlook.it (L.F.) \\ 3 Department of Neurology, "SS Annunziata" Hospital, 66100 Chieti, Italy; antoniodimuzio1@gmail.com \\ * Correspondence: vincenzo19689@gmail.com; Tel.: +39-0916554780
}

check for updates

Citation: Di Stefano, V.; Gagliardo, A.; Barbone, F.; Vitale, M.; Ferri, L.; Lupica, A.; Iacono, S.; Di Muzio, A.; Brighina, F. Median-to-Ulnar Nerve Communication in Carpal Tunnel Syndrome: An Electrophysiological Study. Neurol. Int. 2021, 13, 304-314. https://doi.org/10.3390/ neurolint13030031

Academic Editor: Tibor Hortobagyi

Received: 26 May 2021

Accepted: 2 July 2021

Published: 12 July 2021

Publisher's Note: MDPI stays neutral with regard to jurisdictional claims in published maps and institutional affiliations.

Copyright: (c) 2021 by the authors. Licensee MDPI, Basel, Switzerland. This article is an open access article distributed under the terms and conditions of the Creative Commons Attribution (CC BY) license (https:// creativecommons.org/licenses/by/ $4.0 /)$.

\begin{abstract}
The median-to-ulnar communicating branch (MUC) is an asymptomatic variant of the upper limb innervation that can lead to interpretation errors in routine nerve conduction studies. The diagnosis of carpal tunnel syndrome (CTS) or ulnar nerve lesions can be complicated by the presence of MUC. In this study, we describe electrophysiological features of MUC in CTS patients presenting to our clinic. We enrolled MUB cases from consecutive CTS patients referred to our laboratory between the years 2014 and 2019. MUC was present in 53 limbs (36 patients) from the studied population. MUC was bilateral in 53\% of patients. MUC type II was the most common subtype (74\%), followed by types III and I; more coexisting MUC types were found in the majority of tested limbs. A positive correlation was demonstrated between the severity of CTS and the presence of positive onset, faster $\mathrm{CV}$, or a double component of the compound muscle action potentials. We emphasize the importance of suspecting the presence of MUC in CTS in the presence of a positive onset or a double component in routine motor conduction studies.
\end{abstract}

Keywords: Martin-Gruber anastomosis; carpal tunnel syndrome; ulnar neuropathy at elbow; median nerve; ulnar nerve; neurophysiology

\section{Introduction}

The median-to-ulnar communicating branch (MUC) [1], also known as "MartinGruber anastomosis/communication," is a common anatomical innervation variant of the upper limb in which a crossover of axons passes from the median (MN) to the ulnar nerve (UN) in the forearm; this condition occurs asymptomatically in about $5-40 \%$ of the population and is bilateral in 10-40\% of cases [2-10]. MUC usually goes undetected, but sometimes it is revealed by the unusual distribution of a motor or sensory deficit after injuries of the MN and UN [11]. The fibers involved in MUC, which are usually motor fibers [2,12,13], come from the C8 to T1 nerve roots, travel in the main trunk of the MN or the anterior interosseous nerve, and join the UN in the forearm at 3-10 cm distal to the medial epicondyle of the humerus $[2,6,14,15]$. According with the classification proposed by Oh, three electrophysiological MUC subtypes can be recognized depending on the distribution of the MUC axonal fibers in the hand, with specific electrophysiological features in motor conduction studies of the MN and UN for each MUC subtype [16] (Table 1). In the absence of communication, the stimulation of the $\mathrm{MN}$ and UN evokes a similar response at the wrist and elbow. Conversely, when MUC is present, the response from MN stimulation is smaller at the wrist compared to elbow stimulation, because many axons have already crossed from the MN to the UN [12,16]. The opposite happens with UN stimulation, as the elbow response is smaller because the $\mathrm{UN}$ receives crossing fibers in the forearm, resulting 
in a bigger response at the wrist $[6,17]$. Hence, MUC might be rarely misinterpreted as a conduction block of the UN between the wrist and below-elbow sites [17-20]. Of interest, MUC may lead to interpreting errors during routine nerve conduction studies (NCS) in patients with carpal tunnel syndrome (CTS) $[5,11,12,21,22]$. In fact, in the presence of CTS, the compound motor action potential (CMAP) at the elbow could present an initial positive deflection, thus leading to an apparently fast nerve conduction velocity $(\mathrm{CV})$ of the $\mathrm{MN}$ in the forearm $[5,8,11,21]$. These alterations are not always easy to recognize despite marked discrepancies between clinical and electrodiagnostic findings. Sometimes, failure in diagnosis can result in an underrating of CTS severity or unnecessary surgical decompression in the case of UN neuropathy $[11,17,20]$. In this study, we describe CTS patients with neurophysiological evidence of MUC to characterize its electrophysiological features and its impact in clinical practice.

Table 1. Comparison among different types of median-to-ulnar communicating branch according to MUC classifications.

\begin{tabular}{|c|c|c|c|c|c|}
\hline $\begin{array}{c}\text { Type of } \\
\text { Communication }\end{array}$ & $\begin{array}{c}\text { Frequency in } \\
\text { Healthy Subjects }\end{array}$ & Distribution & Clinical Suspicion & NCS Findings & $\begin{array}{c}\text { Possible } \\
\text { Misdiagnosis }\end{array}$ \\
\hline MUC type I & $\begin{array}{c}2-44 \% \\
{[2,10,13,23-27]} \\
\text { Coexisting MUC II } \\
\text { in } 14-100 \% \text { of cases } \\
{[10,23,25,26]}\end{array}$ & $\begin{array}{l}\text { Proximal median } \\
\text { to distal ulnar } \\
\text { communication } \\
\text { innervating the } \\
\text { hypothenar } \\
\text { muscles. }\end{array}$ & $\begin{array}{l}\text { Absence of } \\
\text { hypothenar } \\
\text { involvement in the } \\
\text { presence of ulnar } \\
\text { nerve damage. }\end{array}$ & $\begin{array}{c}\text { Greater CMAP } \\
\text { amplitude over } \\
\text { ADM recording } \\
\text { when stimulating } \\
\text { the ulnar nerve at } \\
\text { the wrist } \\
\text { compared to } \\
\text { the elbow. }\end{array}$ & $\begin{array}{c}\text { Ulnar neuropathy } \\
\text { at the } \\
\text { elbow/cubital } \\
\text { tunnel syndrome }\end{array}$ \\
\hline MUC type II & $\begin{array}{c}8-58 \% \\
{[2,10,13,23-27]} \\
\text { Coexisting MUC I } \\
\text { in } 9-31 \% \text { of cases } \\
{[10,23,25,26]}\end{array}$ & $\begin{array}{l}\text { Proximal median } \\
\text { to distal ulnar } \\
\text { communication } \\
\text { innervating the } \\
\text { FDI muscle. }\end{array}$ & $\begin{array}{l}\text { Absence of FDI } \\
\text { involvement in the } \\
\text { presence of ulnar } \\
\text { nerve damage. }\end{array}$ & $\begin{array}{c}\text { Greater CMAP } \\
\text { amplitude over } \\
\text { FDI recording } \\
\text { when stimulating } \\
\text { the ulnar nerve at } \\
\text { the wrist } \\
\text { compared to } \\
\text { the elbow. }\end{array}$ & $\begin{array}{c}\text { Ulnar neuropathy } \\
\text { at the } \\
\text { elbow/cubital } \\
\text { tunnel syndrome }\end{array}$ \\
\hline MUC type III & $\begin{array}{c}0.01-30 \% \\
{[2,10,13,24-27]} \\
\text { Coexisting MUC II } \\
\text { in } 20 \% \text { of cases } \\
{[10]}\end{array}$ & $\begin{array}{l}\text { Proximal median } \\
\text { to distal ulnar } \\
\text { communication } \\
\text { innervating the } \\
\text { thenar muscles }\end{array}$ & $\begin{array}{l}\text { Absence of thenar } \\
\text { involvement in the } \\
\text { presence of median } \\
\text { nerve damage. }\end{array}$ & $\begin{array}{l}\text { Greater CMAP } \\
\text { amplitude over } \\
\text { APB recording } \\
\text { when stimulating } \\
\text { the median nerve } \\
\text { at the elbow } \\
\text { compared to } \\
\text { the wrist. }\end{array}$ & $\begin{array}{l}\text { Carpal tunnel } \\
\text { syndrome }\end{array}$ \\
\hline
\end{tabular}

MUC—-median-to-ulnar communicating branch; NCS—nerve conduction studies; FDI—first dorsal interosseus muscle; ADM-abductor digiti minimi muscle; $\mathrm{APB}$-abductor brevis pollicis muscle.

\section{Materials and Methods}

\subsection{Aims of the Study}

In this study, we describe the electrophysiological features of median-to-ulnar nerve communication in a cohort of CTS patients to better characterize MUC's electrophysiological features and its impact in clinical practice. Furthermore, we explore the role of several grades of CTS severity on the presence of MUC and its influence on motor conduction studies parameters for each patient.

\subsection{Participants and Data Collection}

Among patients referred to our electrophysiology laboratory for the evaluation of CTS between 2014 and 2019, we only selected the patients with at least two definite electrodiagnostic criteria for MUC and the clinical diagnosis of CTS [23] (Table 2). Hence, patients with CTS satisfying the criteria for MUC underwent a complete NCS protocol for 
the evaluation of MUC. For each enrolled patient, we only collected data for motor nerves such as CMAP amplitude (measured from the baseline to the negative peak) [9,15,24], distal motor latency (DML) and CV, whereas sensory nerve action potential (SNAP) collection was only performed for the MN to assess CTS severity.

Table 2. Electrodiagnostic criteria for median-to-ulnar communicating branch.

1. Proximal MN evoked CMAP higher at least $2 \mathrm{mV}$ than distal one

2. Initial positive deflection or presence of double component in the MN evoked CMAP at proximal stimulation site recording by $\mathrm{ABP}$

3. $\mathrm{MN}$ motor $\mathrm{CV}$ over $75 \mathrm{~m} / \mathrm{s}$ at proximal site of stimulation

4. Distal UN evoked CMAP recorded from ADM or FDI higher at least $2 \mathrm{mV}$ than proximal one

5. Presence of a measurable potential recording from ADM with proximal MN stimulation

MN-median nerve; UN-ulnar nerve; CMAP—compound motor action potential; CV—conduction velocity; ADM-abductor digit minimi muscle; FDI-first dorsal interosseus muscle.

\subsection{Electrophysiology Procedures}

NCS were performed according to standard procedures (i.e., bipolar surface stimulating electrodes delivering rectangular pulses $0.1-0.5 \mathrm{~ms}$ in duration and recording electrodes placed over the recording site, with a ground electrode placed between recording and stimulation electrodes) $[16,23,24]$. In particular, for MUC detection, the study protocol was defined as follows: (1) stimulation of the $\mathrm{MN}$ at the wrist and elbow and recording from $\mathrm{APB}, \mathrm{ADM}$, and FDI muscles in three different stimulation trials; (2) stimulation of the $\mathrm{UN}$ at the wrist and below the elbow at least $4 \mathrm{~cm}$ distal to the medial epicondyle of the humerus and recording from $\mathrm{APB}, \mathrm{ADM}$, and FDI muscles in three different stimulation trials. As we studied MUC through recordings from APB, ADM, and FDI muscles, we used the classification system presented by Oh (Table 1) [16]. We evaluated several neurophysiological parameters as reliable measures of the communication entity: the presence of a positive onset, a double potential, CV, CMAP amplitude, "gain" in CMAP amplitude obtained by a distal UN stimulation compared to a proximal stimulation, and "drop" in CMAP amplitude obtained by a proximal MN stimulation compared to a distal stimulation. Finally, the severity of CTS was assessed according to consensus criteria [25].

\subsection{Statistical Analyses}

We reported continuous variables as mean with standard deviation (SD) and categorical variables as percentages. We compared categorical variables (presence of double potentials, positive onset, and MUC subtypes) among groups with the Chi-square test, whereas Pearson correlation coefficient was used for grade of correlations between categorical variables. The continue variables were analyzed using the ANOVA, with the between-subjects factor group (5 levels: normal, minimal, slight, moderate, and severe CTS) and the within-subjects factor group (CMAP amplitude, CV, DML, ulnar gain in amplitude, and median drop in amplitude). Statistical analyses were performed using the SPSS software (version 26.0 IBM Statistics, IBM Corp); the level of significance was set at a $p$ value of $<0.05$.

\section{Results}

From 941 patients referred to our laboratory for CTS between 2014 and 2019, we selected 36 patients (53 limbs; 83\% female) affected by CTS and electrodiagnostic evidence of MUC. In particular, MUC was observed in the right upper limb in 53\% of cases and 
was bilateral in 19 patients (52\% of patients; $72 \%$ of examined limbs). Though the MUC II was the most common encountered subtype (74\%), mixed anastomoses were reported in $55 \%$ of explored limbs. No statistical difference was found regarding different MUC subtypes and their combination depending on sex, side (right or left), or laterality (bilateral or monolateral). The detailed distribution of MUC subtypes and the result of NCS in our cohort of 36 patients with CTS and MUC are reported in Tables 3 and 4, respectively.

Table 3. Features of median-to-ulnar communicating branch in 36 patients with carpal tunnel syndrome and MUC. MUC-median-to-ulnar communicating branch.

\begin{tabular}{lcccc}
\hline & MUC I & MUC II & MUC III & Total (Limbs) \\
\hline Limbs $(n, \%)$ & $18(34 \%)$ & $39(74 \%)$ & $32(60 \%)$ & 53 \\
Sex (males, $\%)$ & $2(11 \%)$ & $6(15 \%)$ & $4(13 \%)$ & $9(17 \%)$ \\
Side (right, $\%)$ & $8(44 \%)$ & $19(49 \%)$ & $20(63 \%)$ & $28(53 \%)$ \\
Isolated communication $(n, \%)$ & 0 & $10(26 \%)$ & $11(34 \%)$ & $21(40 \%)$ \\
Coexistent MUC I $(n, \%)$ & $/$ & $18(46 \%)$ & $9(28 \%)$ & $/$ \\
Coexistent MUC II $(n, \%)$ & $18(100 \%)$ & $/$ & $20(63 \%)$ & $/$ \\
Coexistent MUC III $(n, \%)$ & $9(50 \%)$ & $20(51 \%)$ & $/$ & $/$ \\
\hline
\end{tabular}

Table 4. Nerve conduction studies in patients with carpal tunnel syndrome and median-to-ulnar communicating branch. Values are expressed as means with standard deviations or percentages.

\begin{tabular}{|c|c|c|c|c|}
\hline Recording Site & MUC I & MUC II & MUC III & Total Limbs \\
\hline \multicolumn{5}{|l|}{ ADM ulnar nerve } \\
\hline DML (ms) & $2.8 \pm 0.6$ & $2.8 \pm 0.5$ & $2.7 \pm 0.5$ & $2.7 \pm 0.5$ \\
\hline CMAP-AW (mV) & $10.5 \pm 2.3$ & $10.5 \pm 2.4$ & $10.8 \pm 2.0$ & $10.6 \pm 2.3$ \\
\hline CMAP-AE (mV) & $8.9 \pm 2.4$ & $9.1 \pm 2.4$ & $9.2 \pm 2.2$ & $9.1 \pm 2.3$ \\
\hline $\mathrm{CV}(\mathrm{m} / \mathrm{s})$ & $58.0 \pm 7.6$ & $57.8 \pm 4.9$ & $59.5 \pm 4.7$ & $58.7 \pm 6.9$ \\
\hline Positive onset $(n, \%)$ & $2(11 \%)$ & $2(5 \%)$ & $1(3 \%)$ & $4(8 \%)$ \\
\hline Double component $(n, \%)$ & 0 & 0 & 0 & 0 \\
\hline Ulnar Gain in amplitude mV (\%) & $1.7 \pm 0.7(21 \%)$ & $1.2 \pm 0.9(19 \%)$ & $1.4 \pm 0.8(22 \%)$ & $1.2 \pm 0.9(19 \%)$ \\
\hline \multicolumn{5}{|l|}{ ADM median nerve } \\
\hline DML (ms) & $5.6 \pm 2.0$ & $5.1 \pm 1.9$ & $5.2 \pm 2.2$ & $5.1 \pm 1.9$ \\
\hline CMAP-AW (mV) & $0.2 \pm 0.6$ & $0.3 \pm 0.6$ & $0.4 \pm 0.7$ & $0.3 \pm 0.6$ \\
\hline CMAP-AE (mV) & $1.1 \pm 0.7$ & $0.9 \pm 0.7$ & $0.7 \pm 0.7$ & $0.8 \pm 0.7$ \\
\hline Positive onset $(n, \%)$ & $6(33 \%)$ & $6(15 \%)$ & $3(9 \%)$ & $15(28 \%)$ \\
\hline Double component $(n, \%)$ & 0 & 0 & 0 & 0 \\
\hline Median drop in amplitude $\mathrm{mV}(\%)$ & $0.9 \pm 0.4(86 \%)$ & $0.5 \pm 0.5(73 \%)$ & $0.3 \pm 0.4(63 \%)$ & $0.4 \pm 0.5(73 \%)$ \\
\hline \multicolumn{5}{|l|}{ FDI ulnar nerve } \\
\hline DML (ms) & $3.4 \pm 0.3$ & $3.5 \pm 0.4$ & $3.6 \pm 0.5$ & $3.5 \pm 0.4$ \\
\hline CMAP-AW (mV) & $11.9 \pm 4.7$ & $11.2 \pm 4.4$ & $10.4 \pm 3.8$ & $11.3 \pm 4.4$ \\
\hline CMAP-AE (mV) & $7.1 \pm 4.0$ & $7.0 \pm 3.7$ & $6.8 \pm 3.3$ & $7.3 \pm 3.9$ \\
\hline $\mathrm{CV}(\mathrm{m} / \mathrm{s})$ & $55.8 \pm 5.8$ & $54.3 \pm 7.1$ & $52.6 \pm 6.6$ & $54.6 \pm 6.9$ \\
\hline Positive onset $(n, \%)$ & $2(11 \%)$ & $3(8 \%)$ & 0 & $4(8 \%)$ \\
\hline Double component $(n, \%)$ & 0 & 0 & 0 & 0 \\
\hline Ulnar Gain in amplitude mV (\%) & $4.9 \pm 2.4(93 \%)$ & $4.1 \pm 2.0(80 \%)$ & $3.4 \pm 1.5(67 \%)$ & $3.9 \pm 1.1(73 \%)$ \\
\hline \multicolumn{5}{|l|}{ FDI median nerve } \\
\hline DML (ms) & $4.7 \pm 0.8$ & $4.9 \pm 1.1$ & $5.3 \pm 1.5$ & $4.8 \pm 1.1$ \\
\hline CMAP-AW (mV) & $0.6 \pm 4.0$ & $0.7 \pm 0.6$ & $0.8 \pm 1.2$ & $0.8 \pm 0.9$ \\
\hline
\end{tabular}


Table 4. Cont.

\begin{tabular}{|c|c|c|c|c|}
\hline Recording Site & MUC I & MUC II & MUC III & Total Limbs \\
\hline CMAP-AE (mV) & $4.0 \pm 2.6$ & $3.6 \pm 2.2$ & $3.5 \pm 2.0$ & $3.5 \pm 2.2$ \\
\hline Positive onset $(n, \%)$ & 0 & 0 & 0 & 0 \\
\hline Double component $(n, \%)$ & 0 & 0 & 0 & 0 \\
\hline Median drop in amplitude $\mathrm{mV}(\%)$ & $3.3 \pm 2.0(81 \%)$ & $2.9 \pm 1.7(79 \%)$ & $2.6 \pm 1.4(73 \%)$ & $2.7 \pm 1.6(74 \%)$ \\
\hline \multicolumn{5}{|l|}{ APB median nerve } \\
\hline DML (ms) & $5.3 \pm 2.6$ & $5.2 \pm 2.2$ & $6.2 \pm 2.4$ & $5.3 \pm 2.2$ \\
\hline CMAP-AW (mV) & $7.1 \pm 3.1$ & $7.0 \pm 3.5$ & $5.0 \pm 3.4$ & $6.3 \pm 3.7$ \\
\hline CMAP-AE (mV) & $7.1 \pm 3.0$ & $7.4 \pm 3.6$ & $5.4 \pm 3.4$ & $6.6 \pm 4.0$ \\
\hline $\mathrm{CV}(\mathrm{m} / \mathrm{s})$ & $99.9 \pm 58.7$ & $103.1 \pm 118.7$ & $172.8 \pm 113.8$ & $123 \pm 145$ \\
\hline Positive onset $(n, \%)$ & $12(67 \%)$ & $22(56 \%)$ & $28(88 \%)$ & $35(66 \%)$ \\
\hline Double component $(n, \%)$ & $3(17 \%)$ & $5(13 \%)$ & $11(34 \%)$ & $12(23 \%)$ \\
\hline Median drop in amplitude $\mathrm{mV}(\%)$ & $0.1 \pm 0.5(1 \%)$ & $0.4 \pm 0.7(5 \%)$ & $0.5 \pm 0.7(6 \%)$ & $0.5 \pm 0.7(5 \%)$ \\
\hline \multicolumn{5}{|l|}{$A P B$ ulnar nerve } \\
\hline $\mathrm{DML}(\mathrm{ms})$ & $3.1 \pm 0.8$ & $3.3 \pm 0.8$ & $3.2 \pm 0.7$ & $3.2 \pm 0.7$ \\
\hline CMAP-AW (mV) & $4.2 \pm 1.5$ & $4.5 \pm 2.0$ & $4.3 \pm 1.8$ & $4.6 \pm 2.2$ \\
\hline CMAP-AE (mV) & $3.6 \pm 1.4$ & $3.7 \pm 1.5$ & $3.6 \pm 1.4$ & $3.8 \pm 1.6$ \\
\hline Positive onset $(n, \%)$ & $3(17 \%)$ & $9(23 \%)$ & $9(28 \%)$ & $11(21 \%)$ \\
\hline Double component $(n, \%)$ & 0 & 0 & 0 & 0 \\
\hline Ulnar Gain in amplitude mV (\%) & $0.5 \pm 0.6(19 \%)$ & $0.7 \pm 0.7(21 \%)$ & $0.8 \pm 0.6(24 \%)$ & $0.7 \pm 0.7(21 \%)$ \\
\hline
\end{tabular}

MUC - median-to-ulnar communicating branch; ADM—abductor digiti minimi muscle; FDI-first dorsal interosseus muscle; APBabductor brevis pollicis muscle; CMAP-AW/E-compound motor action potential at the wrist/elbow; ADM ulnar nerve- ulnar nerve stimulation while recording from ADM muscle; ADM median nerve-median nerve stimulation while recording from ADM muscle; FDI ulnar nerve-ulnar nerve stimulation while recording from FDI muscle; FDI median nerve-median nerve stimulation while recording from FDI muscle; APB median nerve-median nerve stimulation while recording from APB muscle; APB ulnar nerve-ulnar nerve stimulation while recording from APB muscle; DML—distal motor latency; CV—conduction velocity.

\subsection{Recordings from ADM Muscle}

Among patients with MUC I, the proximal and distal stimulation of the UN yielded a negative response with an average CMAP amplitude significantly increased at the wrist $(+21 \%, 1.68 \pm 0.66 \mathrm{mV})$ compared to below the elbow $(p=0.046)$, whereas the stimulation of $\mathrm{MN}$ at the wrist evoked a small positive response $(0.5-1 \mathrm{mV})$ in 16 limbs $(30 \%)$, with a higher CMAP amplitude at the elbow than wrist stimulation $(-86 \%)(p=0.0001)$.

\subsection{Recordings from FDI Muscle}

Among patients with MUC II, the proximal (below elbow) and distal (wrist) stimulation of the UN produced a negative response in $92 \%$ of patients, with an average of CMAP amplitude significantly increased at the wrist $(+80 \%, 4.14 \pm 2.0 \mathrm{mV})$ compared to below the elbow $(p=0.0001)$, whereas the stimulation of MN at the wrist evoked a small negative response in 51 examined limbs $(96 \%)$, with a higher average of CMAP amplitude at the elbow than wrist stimulation $(p=0.0001)$.

\subsection{Recordings from APB Muscle}

Among patients with MUC III, the stimulation of the MN produced a positive onset in $35 \mathrm{arms}(66 \%)$, while a double component was demonstrated in a further 12 limbs (22\%). Though the averages of CMAP amplitude resulting from the stimulation of the MN and UN were not significantly different between the wrist and elbow, the average of CMAP amplitude was slightly reduced at below the elbow compared to the wrist $(+24 \%)$ after proximal and distal UN stimulation. Moreover, in the presence of MUC III, there was a 
significant increase in CV upon MN stimulation compared to patients without MUC III $(p<0.0001)$.

\subsection{Severity of CTS and Presence of MUC Subtypes}

In our cohort, different severity grades of CTS were found: severe (12 limbs; $23 \%$ ), moderate (24 limbs; $46 \%$ ), slight (5 limbs; $9 \%$ ), minimal (6 limbs; $11 \%$ ), and normal (6 limbs; $11 \%)$. Patients with CTS showed a higher incidence of MUC III ( $\mathrm{F}=2.87 ; p=0.034)$, whereas patients with normal findings on CTS showed a reduced incidence of type III with respect to the ones with severe CTS $(p=0.018)$. Furthermore, the presence of double potential from median stimulation recording from $\mathrm{APB}$ appeared more frequently in patients with severe CTS with respect to normal $(p<0.0001)$, minimal $(p=0.02)$, slight $(p=0.0001)$, and moderate $(p<0.0001)$ severity. The CV calculated from MN stimulation recording from APB appeared faster in patients with severe CTS with respect to normal $(p=0.004)$, minimal $(p=0.007)$, slight $(p=0.011)$, and moderate $(p<0.0001)$ severity; the DML obtained from median stimulation recording from APB appeared more prolonged in patients with severe CTS with respect to normal $(p<0.0001)$, minimal $(p<0.0001)$, slight $(p<0.0001)$, and moderate $(p<0.0001)$ severity; the CMAP amplitude at the wrist from median stimulation recording from APB appeared significantly reduced in patients with moderate $(p=0.008)$ and severe $(p=0.003)$ severity with respect to minimal CTS severity; the CMAP amplitude at the elbow from median stimulation recording from APB appeared significantly reduced in patients with moderate $(p=0.034)$ and severe $(p=0.008)$ severity with respect to minimal CTS severity; the DML of the CMAP obtained from UN stimulation recording from FDI appeared significantly prolonged in patients with moderate and severe severity grades compared to minimal $(p=0.02 ; p=0.046)$ and slight $(p=0.16 ; p=0.038)$ CTS severity grades. A positive linear correlation between the DML and CV obtained from MN stimulation recording from APB was demonstrated $(r=0.512$ and $p<0.0001$; Figure 1, panel A).
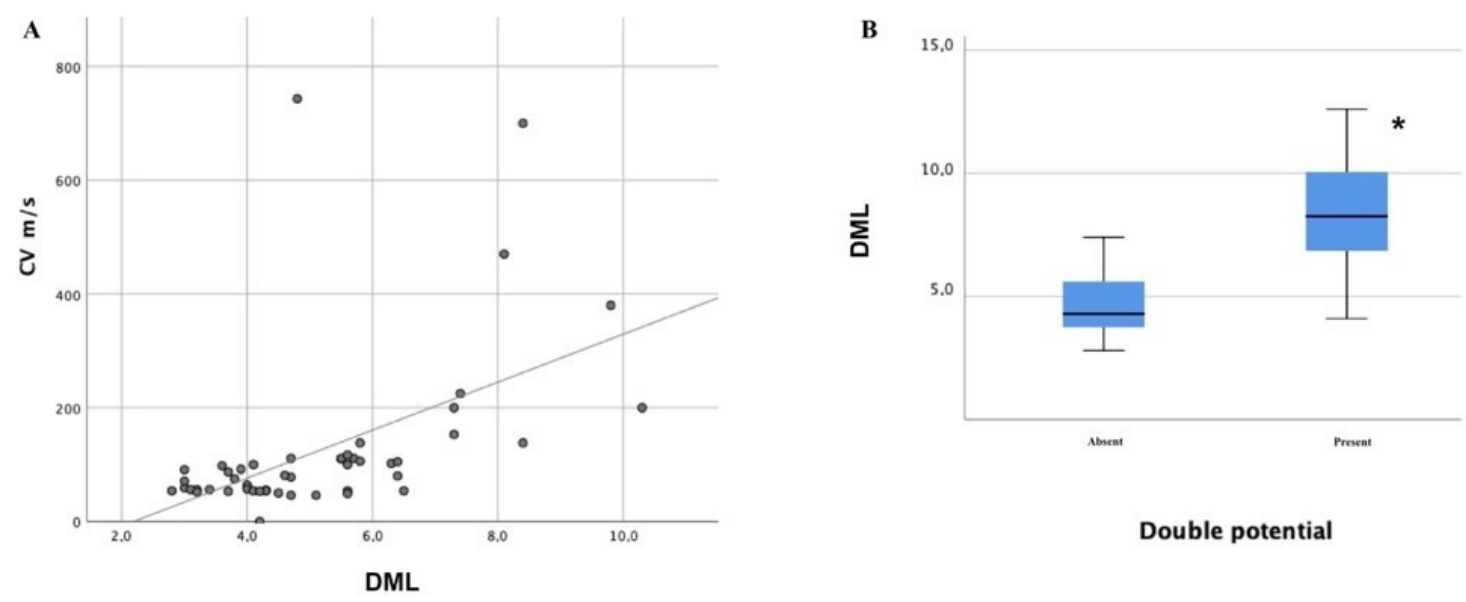

Figure 1. Correlation between DML, double potential, and CV in patients with MUC and CTS. (A) The linear correlation between median nerve CV and DML from NCS recording from APB. (B) The distribution of double potentials among MUC patients depending on the DML of the median nerve. MUC—-median-to-ulnar communicating branch; CTS—carpal tunnel syndrome; CV—conduction velocity; DML—distal motor latency; NCS—nerve conduction studies; APB—abductor brevis pollicis muscle; ${ }^{*} p<0.0001$.

\section{Discussion}

Several studies have explored the prevalence and characteristics of the MUC among healthy subjects $[3,4,7,10,13,22,28-30]$, whereas subjects with MN or UN injuries were often excluded. Only a few studies have explored the effects of such communication in a population of patients affected by CTS $[5,11,12,21]$. Of interest, a study on 63 consecutive patients with bilateral CTS reported signs of MUC in $25 \%$ of patients, pointing out that the association between MUC and CTS is not rare [5], and if it occurs, additional electro- 
physiological changes may appear with the risk of the underestimation of CTS or even false-negative results on NCS [5,11,21]. For instance, patients with CTS and MUC type III present a near normal proximal motor latency of the $\mathrm{MN}$ in the presence of prolonged DML, resulting in apparently faster CV [11]. In addition, patients with MUC and CTS might have the partial or complete sparing of the thenar muscles due to the crossover of fibers to the UN [16]. Moreover, MUC type I might mimic an ulnar neuropathy at the elbow in which a reduced-absent response would be expected proximally with the sparing of wrist responses. In this case, the differential diagnosis between ulnar neuropathy at the elbow and MUC type I might be obtained through the stimulation of the MN at the elbow, evoking a wrist response that, when added to the one obtained by stimulation of the UN at the elbow, would equal the response obtained from UN wrist stimulation (Figure 2) [17,26,29].

A

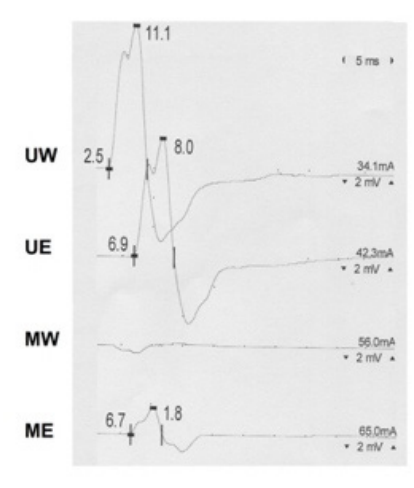

ADM
B

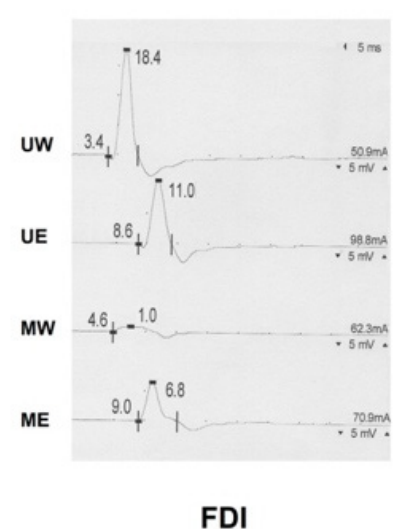

C

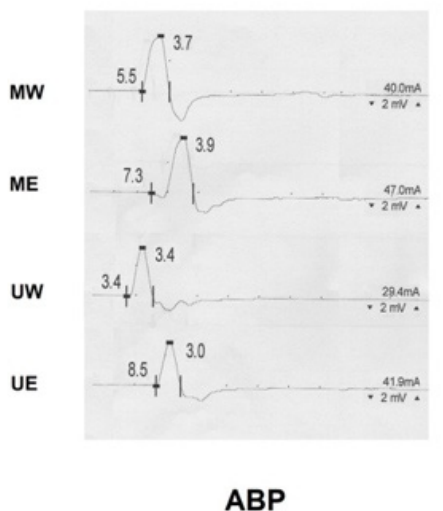

Figure 2. Motor nerve conduction studies from patients with MUC type I (A), II (B), and III (C). (A) Recording from ADM, a difference of $3.1 \mathrm{mV}$ was recognizable between $\mathrm{U}-\mathrm{W}$ and U-BE and an MUC component of $1.8 \mathrm{mV}$ was demonstrated. (B) Recording from FDI, a significant drop of $7.4 \mathrm{mV}$ between U-W and U-BE corresponded to a MUC of $6.8 \mathrm{mV}$, as demonstrated upon ME stimulation. (C) A positive onset was evident upon ME but not MW stimulation. MUC-median-toulnar communicating branch; ADM—abductor digiti minimi muscle; FDI—first dorsal interosseus muscle; APB—abductor brevis pollicis muscle; $\mathrm{U}-\mathrm{W}$ - ulnar wrist; $\mathrm{U}-\mathrm{BE}$ — ulnar below elbow; MW—-median wrist; ME—median elbow.

We confirmed that FDI is the most common MUC-innervated muscle, so is the most useful recording site for the detection of MUC, especially when the FDI atrophy is not severe. A significant increase in the CMAP amplitude at the wrist, compared to the elbow could be easily found while stimulating the UN and recording from FDI and ADM, though not while recording from APB. In our cohort of MUC and CTS patients, there was not a more affected side, according to the existing evidence $[5,6,26]$, although a few studies in healthy subjects have described a slight prevalence of MUC in the right hand $[7,10]$. Moreover, we reported MUC III in $60 \%$ of patients, and several MUC types often coexisted in the same limb (Table 3), in contrast with a majority of the existent studies [10,29]. This aspect is very relevant because many studies on MUC have only considered recordings from APB [11,21,31] or ADM/FDI [18,20,26], and some concern may arise about mistakes in interpreting NCS findings if the possibility of different MUC subtypes is not considered. We found a significant increase in the CMAP amplitude at the wrist compared to below the elbow while stimulating the UN and recording from MUC-innervated muscles. In particular, the best increase in the CMAP amplitude from UN stimulation was detectable from FDI with lower yet significant increases on ADM recordings (Table 4). However, we did not recognize a significant drop in amplitude upon the stimulation of the MN corresponding to the UN gain while recording from APB; indeed, a less prominent drop in amplitude was recorded after the stimulation of the MN (Table 4). This finding was probably due to the fact that the MN neuropathy below the carpal canal may have affected 
CMAP amplitudes in patients with moderate and severe degrees, making comparisons between MN (affected) and UN (not affected) more difficult. Gutmann et al. attributed this finding to an increased synchronization, as the CMAP tends to have a higher amplitude when the nerve is stimulated distally compared to proximally [5]. Another explanation could be found in the "Riche-Cannieu anastomosis," a thenar communicating branch of the ulnar nerve $[1,32]$ that usually results in a slightly higher amplitude of the APB-CMAP with UN stimulation at the wrist than the elbow $[2,15,23]$. Conversely, we found further reliable features in patients with more severe degrees of CTS (Figure 3 and Table 4).

A

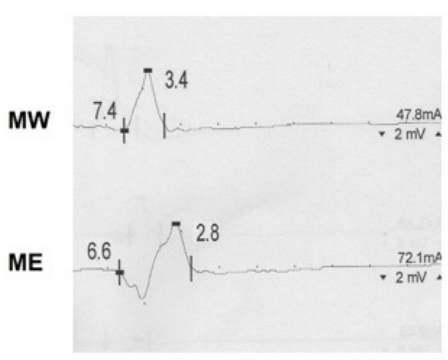

ABP

C

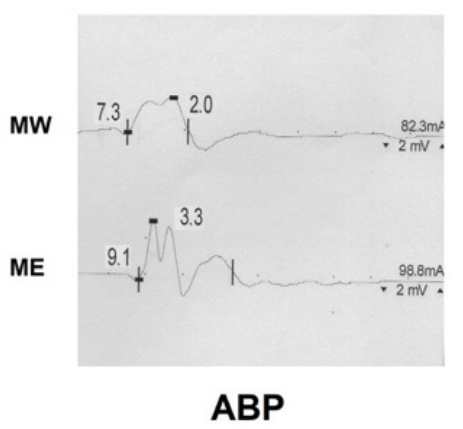

B

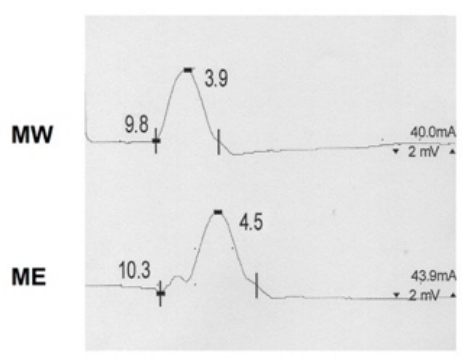

ABP
D

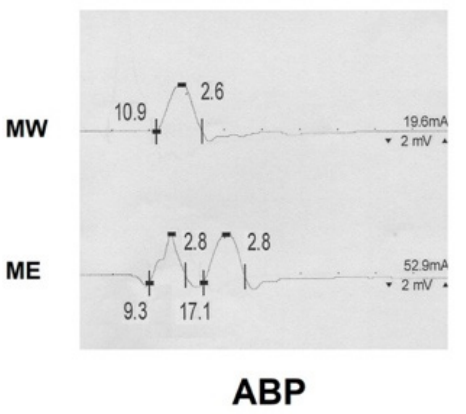

Figure 3. Motor nerve conduction studies from patients with MUC type III and severe CTS. (A) A significant positive onset was evident upon ME but not at MW stimulation. (B-D) A double component was demonstrated upon ME stimulation. $(\mathbf{B}, \mathbf{C})$ The more prolonged the DLM was, the more the two components were spaced apart until they were even separated from the baseline (D). MUCmedian-to-ulnar communicating branch; APB—abductor brevis pollicis muscle; MW—median wrist; ME—median elbow; DML—distal motor latency.

Previous studies have already described how in the case of moderate and severe CTS degrees, there is a higher CMAP amplitude at the elbow with an initial positive deflection (Figures 2 and 3), which is not seen at the wrist $[5,12,21]$. The reason for this artefact is that MN axons travelling slower through the carpal canal are overcome by the MUC medianinnervated ulnar fibers (not-compressed) being conducting quickly [5,12,21]. In fact, NCS from APB by elbow stimulation record the summation of the normal median response (conducting slower in CTS) and the volume-conducted CMAP recorded from muscles innervated by the anastomotic branch (conducting faster); as a result, the faster volumeconducted response is manifested by an initial positive deflection [16,21]. Additionally, in the presence of a positive onset of the MN CMAP, it might be very difficult to define the real onset of the CMAP and, consequently, the DML, which might be underestimated with a possible underrating of a CTS according to international classifications for severity [33]. 
This finding has been rarely reported from studies in healthy subjects, where the volumeconducted response has only caused a higher amplitude of the recorded CMAP [21,23]. Hence, the positive deflection alone should not be taken as evidence for MUC. As a further clue for identification, MUC can also cause an apparently fast nerve CV of the MN in the forearm due to the relative sparing of proximal motor latency with respect to the DML $[5,8,11,15,21,34]$. Of interest, we described a positive correlation between the DML and $\mathrm{CV}$ recorded from $\mathrm{APB}$ upon MN stimulation (Figure 1, panel A); as a result, the more affected CTS patients tend to have a more prolonged DML and apparently faster $\mathrm{CV}$ upon MN studies if measured from the first positive deflection. Furthermore, if the DML is prolonged enough, the cancellation of phase does not occur and a "double CMAP" can be seen in routine studies. Of interest, the frequency of a double component among our patients was increased the more the prolongation of DML was pronounced (Figure 1, panel B). In these more severe CTS, the MUC branch is significant faster than the CMAP of the $\mathrm{MN}$, so the two components are entirely separated with a return to the baseline between each response (Figure 3). This finding cannot be explained by any other physiological or pathological condition [6] and should be considered pathognomonic of MUC III [21].

\section{Limitations}

In our study, MUC had an overall lower prevalence than expected ( $3 \%$ of limbs and $4 \%$ of patients), and we think that this might have been due to selection bias consistent in patient's selection among ones with a clinical diagnosis of CTS and previous NCS demonstrating MUC, with an underestimation of the real prevalence of MUC and especially MUC type I and II in real life. Indeed, in our cohort, MUC type III there was more common than other subtypes. Other limitations in patient selection might have been the little attention at the first evaluation paid to the possibility of MUC and the arbitrary limits for the differences in amplitude between the CMAPs at the wrist and elbow stimulation of MN. Furthermore, it has been reported that MUC can alter NCS only if the anastomotic branch contributes more than $5-10 \%$ of the total innervations of hand muscles [6]; as a consequence, very thin anastomotic branches are really difficult to detect by electrodiagnostic testing and may have escaped our detection. Moreover, because of we chose the wrist and elbow as stimulation sites for NCS, the very proximal MUC might have escaped detection. We did not consider many factors that may have led to an underestimation of MUC, e.g., height and body weight; indeed, a great representativity of the adipose and muscle tissues might have led to a reduction in CMAP amplitude after proximal stimulation. Finally, a positive wave in median nerve EDX might occur in individuals without MUC as a sign of muscle volume conduction or sensory pre-wave, or it might be generated by the UN co-stimulation of the flexor pollicis brevis. However, in our opinion, these considerations are true in normal NCS and become less relevant in the presence of prominent positive waves in moderate and severe CTS.

\section{Conclusions}

The anastomoses between the $\mathrm{MN}$ and $\mathrm{UN}$ are usually silent, but they might cause difficulties in interpreting nerve conduction studies, thus leading to misdiagnosis and improper treatment. Indeed, MUC should be always excluded before an ulnar neuropathy at the elbow is confirmed. Additionally, MUC might lead to underestimation in the CTS severity; in these cases, the detection of a positive onset of the CMAP from median nerve stimulation at the elbow, as well as, a paradoxical normal proximal motor latency with prolonged DML and the detection of a double component, might offer reliable clues to identify the presence of MUC in this special population of patients, thus preventing the misinterpretation of electrophysiological data. In particular, the detection of a positive onset or an increased CV can be an important supporting feature in patients with combined CTS and MUC III; in most severe cases of CTS, the presence of a double component is pathognomonic of MUC. Good knowledge of electrodiagnostic features of MUC can 
ensure an accurate interpretation of NCS in patients affected by entrapment neuropathies, especially in CTS.

Author Contributions: Conceptualization, V.D.S. and A.D.M.; methodology, V.D.S.; software, V.D.S.; validation, A.D.M. and F.B. (Filippo Brighina); formal analysis, V.D.S.; investigation, V.D.S.; resources, A.D.M.; data curation, V.D.S., F.B. (Filomena Barbone), M.V., L.F. and A.G.; writing—original draft preparation, V.D.S.; writing-review and editing, S.I., A.L., F.B. (Filomena Barbone), M.V., L.F. and A.G.; visualization, F.B. (Filippo Brighina); supervision, A.G., F.B. (Filippo Brighina), and A.D.M.; project administration, V.D.S. All authors have read and agreed to the published version of the manuscript.

Funding: This research received no external funding.

Institutional Review Board Statement: The study was conducted according to the guidelines of the Declaration of Helsinki, and approved by the Ethics Committee of University of Palermo "Palermo I" (protocol code 5/2020 approved on 20 May 2020).

Informed Consent Statement: Informed consent was obtained from all subjects involved in the study.

Data Availability Statement: The data that support the findings of this study are available from the corresponding author upon reasonable request.

Conflicts of Interest: The authors declare no conflict of interest.

\section{References}

1. Ten Donkelaar, H.J.; Kachlík, D.; Tubbs, R.S. An Illustrated Terminologia Neuroanatomica; Springer International Publishing: Basel, Switzerland, 2018; Volume XVII, p. 491.

2. Roy, J.; Henry, B.M.; Pẹkala, P.A.; Vikse, J.; Saganiak, K.; Walocha, J.A.; Tomaszewski, K.A. Median and ulnar nerve anastomoses in the upper limb: A meta-analysis. Muscle Nerve 2015, 54, 36-47. [CrossRef] [PubMed]

3. Mannerfelt, L. Studies on the Hand in Ulnar Nerve Paralysis: A Clinical-Experimental Investigation in Normal and Anomalous Innervation. Acta Orthop. Scand. 1966, 37, 3-176. [CrossRef] [PubMed]

4. Crutchfield, C.A.; Gutmann, L. Hereditary aspects of median-ulnar nerve communications. J. Neurol. Neurosurg. Psychiatry 1980, 43, 53-55. [CrossRef] [PubMed]

5. Gutmann, L. Median-ulnar nerve communications and carpal tunnel syndrome. J. Neurol. Neurosurg. Psychiatry 1977, 40, 982-986. [CrossRef]

6. Lee, K.-S.; Oh, C.-S.; Chung, I.-H.; Sunwoo, I.-N. An anatomic study of the Martin-Gruber anastomosis: Electrodiagnostic implications. Muscle Nerve 2004, 31, 95-97. [CrossRef]

7. Sarikcioglu, L.; Sindel, M.; Ozkaynak, S.; Aydin, H. Median and ulnar nerve communication in the forearm: An anatomical and electrophysiological study. Med. Sci. Monit. 2003, 9, 29-35.

8. Cavalheiro, C.S.; Filho, M.R.; Pedro, G.; Caetano, M.F.; Vieira, L.A.; Caetano, E.B. Clinical repercussions of Martin-Gruber anastomosis: Anatomical study. Rev. Bras. Ortop. 2016, 51, 214-223. [CrossRef]

9. Van Dijk, J.G.; Bouma, P.A.D. Recognition of the Martin-Gruber anastomosis. Muscle Nerve 1997, 20, 887-889. [CrossRef]

10. Hefny, M.; Sallam, A.; Abdellatif, M.; Okasha, S.; Orabi, M. Electrophysiological Evaluation and Clinical Implication of MartinGruber Anastomosis in Healthy Subjects. J. Hand Surg. 2020, 25, 87-94. [CrossRef]

11. Iyer, V:; Fenichel, G.M. Normal median nerve proximal latency in carpal tunnel syndrome: A clue to coexisting Martin-Gruber anastomosis. J. Neurol. Neurosurg. Psychiatry 1976, 39, 449-452. [CrossRef]

12. Simonetti, S.; Krarup, C. Unusual ulnar sensory innervation and Martin-Gruber anastomosis in a patient with a carpal tunnel syndrome. J. Neurol. 2000, 247, 141-142. [CrossRef]

13. Amoiridis, G.; Vlachonikolis, I.G. Verification of the median-to-ulnar and ulnar-to-median nerve motor fiber anastomosis in the forearm: An electrophysiological study. Clin. Neurophysiol. 2003, 114, 94-98. [CrossRef]

14. Marras, C.; Midroni, G. Proximal Martin-Gruber anastomosis mimicking ulnar neuropathy at the elbow. Muscle Nerve 1999, 22, 1132-1135. [CrossRef]

15. Uncini, A.; Lange, D.J.; Lovelace, R.E. Anomalous intrinsic hand muscle innervation in median and ulnar nerve lesions: An electrophysiological study. Neurol. Sci. 1988, 9, 497-503. [CrossRef]

16. Oh, S.J. Clinical Electromyography: Nerve Conduction Studies, 3rd ed.; Lippincott Williams \& Wilkins: Philadelphia, PA, USA, 2003; p. 848.

17. Cho, N.S.; Kim, D.H.; Kim, M.Y.; Park, B.K. Electrophysiological and ultrasonographic findings in ulnar neuropathy with martin-gruber anastomosis. Muscle Nerve 2013, 47, 604-607. [CrossRef]

18. Whitaker, C.H.; Felice, K.J. Apparent conduction block in patients with ulnar neuropathy at the elbow and proximal Martin-Gruber anastomosis. Muscle Nerve 2004, 30, 808-811. [CrossRef] 
19. Kim, B.J.; Kim, D.H. Ulnar neuropathy around the mid-arm combined with martin-gruber anastomosis. Ann. Rehabil. Med. 2012, 36, 719-723. [CrossRef]

20. Burakgazi, A.Z.; Russo, M.; Bayat, E.; Richardson, P.K. Underrecognized anomaly: Proximal martin-gruber anastomosis at the elbow. J. Clin. Neurophysiol. 2014, 31, 31-34. [CrossRef] [PubMed]

21. Rubin, D.I.; Dimberg, E.L. Martin-gruber anastomosis and carpal tunnel 42: Morphologic clues to identification. Muscle Nerve 2010, 42, 457-458. [CrossRef] [PubMed]

22. Kayamori, R. Electrodiagnosis in Martin-Gruber anastomosis. Nihon Seikeigeka Gakkai Zasshi 1987, 61, 1367-1372. [PubMed]

23. Kimura, I.; Ayyar, D.R.; Lippmann, S.M. Electrophysiological verification of the ulnar to median nerve communications in the hand and forearm. Tohoku J. Exp. Med. 1983, 141, 269-274. [CrossRef]

24. Kimura, J. Electrodiagnosis in Diseases of Nerve and Muscle. In Electrodiagnosis in Diseases of Nerve and Muscle; Oxford University Press: Oxford, UK, 2014.

25. Rempel, D.; Evanoff, B.A.; Amadio, P.C.; De Krom, M.; Franklin, G.; Franzblau, A.; Gray, R.; Gerr, F.; Hagberg, M.; Hales, T.; et al. Consensus criteria for the classification of carpal tunnel syndrome in epidemiologic studies. Am. J. Public Health 1998, 88, 1447-1451. [CrossRef]

26. Uchida, Y.; Sugioka, Y. Electrodiagnosis of Martin-Gruber connection and its clinical importance in peripheral nerve surgery. J. Hand Surg. 1992, 17, 54-59. [CrossRef]

27. Wilbourn, A.J.; Lambert, E. The Forearm Median-to-Ulnar Nerve Communication; Eiectrodiagnostic Aspects. Scientific Program of the American Academy of Neurology Twenty-Eighth Annual Meeting. In Neurology; Ovid Technologies (Wolters Kluwer Health): New York City, NY, USA, 1976; p. 342.

28. Erdem, H.R.; Ergun, S.; Erturk, C.; Ozel, S. Electrophysiological Evaluation of the Incidence of Martin-Gruber Anastomosis in Healthy Subjects. Yonsei Med. J. 2002, 43, 291-296. [CrossRef]

29. Kate, N.; Teli, C.; Gajbhiye, R.; Ambareesha, K.; Suresh, M. A study to analyze the prevalence of nervous anastomosis (MartinGruber) in medical students. Natl. J. Physiol. Pharm. Pharmacol. 2015, 5, 185. [CrossRef]

30. Khosrawi, S.; Kianimehr, L.; Andalib, S. The prevalence of Martin-Gruber anastomosis in Iranian subjects by electrodiagnostic criteria. Iran. J. Neurol. 2015, 14, 231-232.

31. Kimura, J.; Murphy, M.J.; Varda, D.J. Electrophysiological Study of Anomalous Innervation of Intrinsic Hand Muscles. Arch. Neurol. 1976, 33, 842-844. [CrossRef] [PubMed]

32. Kachlik, D.; Musil, V.; Baca, V. Contribution to the anatomical nomenclature concerning upper limb anatomy. Surg. Radiol. Anat. 2016, 39, 405-417. [CrossRef] [PubMed]

33. Padua, L.; Coraci, D.; Erra, C.; Pazzaglia, C.; Paolasso, I.; Loreti, C.; Caliandro, P.; Hobson-Webb, L.D. Carpal tunnel syndrome: Clinical features, diagnosis, and management. Lancet Neurol. 2016, 15, 1273-1284. [CrossRef]

34. Kimura, J. Collision technique: Physiologic block of nerve impulses in studies of motor nerve conduction velocity. Neurology 1976, 26, 680. [CrossRef] [PubMed] 